\title{
Blood ethanol concentrations during and following constant-rate intravenous infusion of alcohol
}

\author{
Blood ethanol concentrations were determined in 7 subjects during and subsequent to a \\ $2-h r$ constant-rate intravenous infusion of ethyl alcohol $(8 \% \mathrm{~V} / \mathrm{V})$. Eight to 10 capillary \\ blood samples were collected during the infusion and 10 to 21 samples were obtained \\ after the infusion ceased. Thus, the total time course of blood ethanol concentrations in \\ man was defined, both during and postinfusion. Blood ethanol concentration data from \\ each of 6 subjects were fitted simultaneously to the two equations for the one-compartment \\ open model with zero order input and Michaelis-Menten elimination kinetics. The \\ average $V_{m}[0.232 \mathrm{mg} /(\mathrm{ml} \times \mathrm{hr})]$ and $K_{m}[0.0821 \mathrm{mg} / \mathrm{ml}]$ obtained from these fittings \\ correspond very closely with corresponding values estimated by the fitting of all the \\ mean concentration-time data obtained following oral administration of 4 different doses \\ of ethanol to 8 other fasting subjects in another study. A disproportionate increase in \\ area under the concentration-time curve with increase in dose $(\mathrm{gm} / \mathrm{kg})$ was observed \\ in a single subject who was infused with equal volumes of a $4 \%$ and an $8 \%(\mathrm{~V} / \mathrm{V})$ \\ ethanol solution at the same constant rate.
}

\author{
Paul K. Wilkinson, Ph.D.," Allen J. Sedman, Ph.D.,"* Ermelinda Sakmar, B.S., \\ Robert H. Earhart, M.D., Donald J. Weidler, M.D., Ph.D., and John G. Wagner, Ph.D. \\ Ann Arbor, Mich. \\ College of Pharmacy and Upjohn Center for Clinical Pharmacology, The University of Michigan
}

Many studies of blood alcohol concentrations in man have been reported, but most of these data were collected following the oral administration of ethyl alcohol to fasting individuals

\footnotetext{
Supported partly by Grant No. I R0I AA 00683-01Al from the National Institute on Alcohol Abuse and Alcoholism, Alcohol, Drug Abuse and Mental Health Administration, and partly by Public Health Service Grant No. 5P11 GM15559.

Received for publication Sept. 2, 1975.

Accepted for publication Nov. 15, 1975.

Reprint requests to: The Upjohn Center for Clinical Pharmacology, The University of Michigan Medical Center, Ann Arbor, Mich. 48109.

*Present address: School of Pharmacy, Auburn University, Auburn, Ala. 36830.

** Present address: Washington University, School of Medicine, St. Louis, Mo. 63110.
}

or in various combinations with several different food test meals. Recently, blood ethanol concentration-time data have been reported in studies involving the intravenous concentration of ethanol to human subjects by rapid infu$\operatorname{sion}^{2,4,6,7}$ and by constant-rate infusion over extended periods. ${ }^{11-13,23}$ Most of this work pertained to ethanol as an anesthetic agent. In this regard, Dundee and co-workers ${ }^{2-7}$ reviewed the literature in a historical accounting of alcohol anesthesia.

Traditionally, it has been assumed that the kinetics of elimination of ethanol from the blood of animals and human subjects can be described as zero order, i.e., independent of 
Table I. Summary of administered doses, areas under the concentration-time curves, and peak blood ethanol concentrations following the 2-hr intravenous infusion of $720 \mathrm{ml}$ of $8 \% \mathrm{~V} / \mathrm{V}$ ethanol in physiological saline to 6 adult male subjects

\begin{tabular}{c|c|c|c|c}
\hline Subject & $\begin{array}{c}\text { Body wt. } \\
(\mathrm{kg})\end{array}$ & $\begin{array}{c}\text { Dose } \\
(\mathrm{gm} \text { abs. alc/kg })\end{array}$ & $\left(\frac{\text { Area }^{*}}{\mathrm{mg}} \times \mathrm{hr}\right)$ & $\begin{array}{c}\text { Peak } \dagger \\
(\mathrm{mg} / \mathrm{ml})\end{array}$ \\
\hline 1 & 79.6 & 0.5604 & 1.986 & 0.67 \\
2 & 88.6 & 0.5166 & 1.738 & 0.63 \\
3 & 79.6 & 0.5945 & 2.586 & 0.84 \\
4 & 75.0 & 0.6016 & 3.030 & 0.81 \\
5 & 75.0 & 0.6206 & 1.941 & 0.67 \\
6 & 82.7 & 0.5784 & 2.392 & 0.80 \\
Average & 80.1 & 0.5787 & 2.279 & 0.74 \\
C.V. (\%) & 6.4 & 6.3 & 21.2 & 12.1 \\
\hline
\end{tabular}

* The area under the capillary ethanol concentration-time curve estimated by trapezoidal rule.

$\dagger$ The peak concentration achieved at the time that the infusion pump was tumed off.

\section{Schema I}

DURING INFUSION

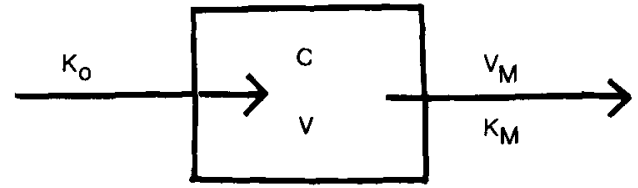

AFTER INFUSION CEASES:

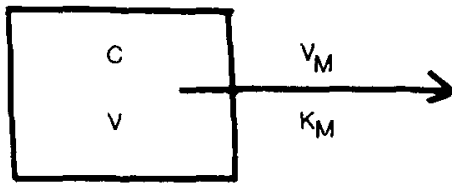

the blood concentration (above about 2 to 3 $\mathrm{mM}$ or 0.09 to $0.14 \mathrm{mg} / \mathrm{ml}$ ). This concept (zero order elimination), first postulated by Widmark, ${ }^{28}$ still persists ${ }^{10},{ }^{19}$ despite several studies $^{8}, 14,17,21,29$ that suggest nonzero order elimination kinetics. Wagner and associates ${ }^{27}$ reported substantial evidence that the elimination of ethanol from the blood of man obeys Michaelis-Menten kinetics and not zero order kinetics.

The available data in the literature have two major shortcomings. These are: (1) the entire time courses of blood ethanol concentrations following oral administration were not measured, and generally only higher terminal blood ethanol concentrations, which appear to be pseudolinear, were reported-there is evidence
Table II. Mean capillary ethanol concentrations at indicated sampling times during and following the 2-hr intravenous infusion of $720 \mathrm{ml}$ of $\mathrm{V} / \mathrm{V}$ ethanol in physiological saline to 6 adult male subjects

\begin{tabular}{|c|c|c|c|}
\hline Time $(h r)$ & Mean $(\mathrm{mg} / \mathrm{ml})$ & $S D^{*}$ & $C . V . \dagger(\%)$ \\
\hline 0.0 & 0.0 & 0.0 & 0.0 \\
\hline 0.083 & 0.063 & 0.027 & 42.5 \\
\hline 0.25 & 0.16 & 0.05 & 30.7 \\
\hline 0.5 & 0.26 & 0.07 & 26.0 \\
\hline 0.75 & 0.37 & 0.07 & 19.5 \\
\hline 1.0 & 0.46 & 0.05 & 11.5 \\
\hline 1.5 & 0.59 & 0.08 & 12.9 \\
\hline 2.0 & 0.74 & 0.09 & 12.2 \\
\hline 2.083 & 0.70 & 0.08 & 11.3 \\
\hline 2.167 & 0.66 & 0.08 & 12.6 \\
\hline 2.25 & 0.63 & 0.10 & 16.3 \\
\hline 2.5 & 0.58 & 0.07 & 12.9 \\
\hline 2.75 & 0.55 & 0.08 & 15.1 \\
\hline 3.0 & 0.50 & 0.08 & 16.8 \\
\hline 3.5 & 0.43 & 0.09 & 19.9 \\
\hline 4.0 & 0.35 & 0.09 & 24.5 \\
\hline 4.5 & 0.28 & 0.09 & 32.6 \\
\hline 5.0 & 0.18 & 0.09 & 49.1 \\
\hline 5.25 & 0.15 & 0.09 & 61.3 \\
\hline 5.5 & 0.11 & 0.10 & 85.2 \\
\hline 5.75 & 0.076 & 0.081 & 106.0 \\
\hline 6.0 & 0.052 & 0.060 & 117.0 \\
\hline 6.25 & 0.036 & 0.047 & 132.0 \\
\hline 6.5 & 0.025 & 0.038 & 154.0 \\
\hline 6.75 & 0.013 & 0.023 & 177.0 \\
\hline 7.0 & 0.010 & 0.019 & 188.0 \\
\hline 7.25 & 0.0066 & 0.0149 & 225.0 \\
\hline 7.5 & 0.0040 & 0.0098 & 245.0 \\
\hline 7.75 & 0.0028 & 0.0069 & 245.0 \\
\hline
\end{tabular}

* SD: standard deviation.

$\dagger$ C. $V .:$ coefficient of variation $=\frac{S D}{\text { Mean }} \times 100$. 


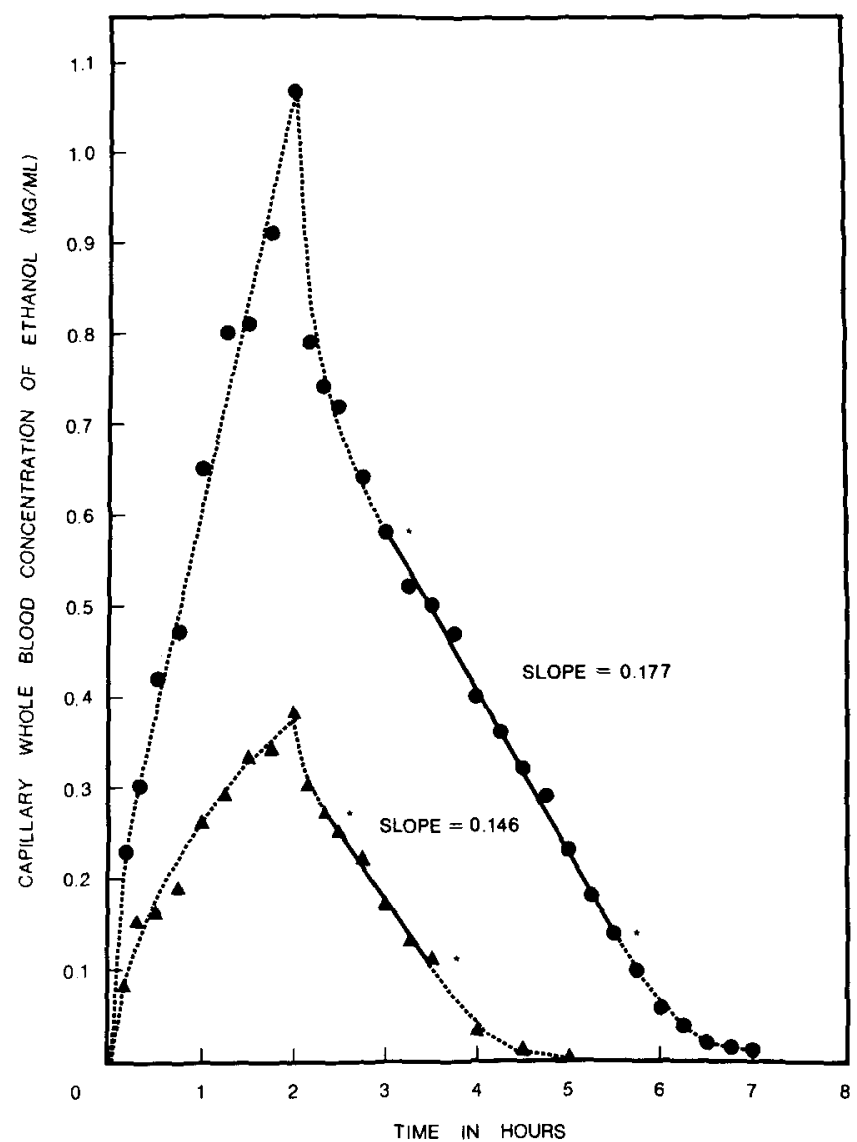

Fig. 1. Capillary blood ethanol concentrations measured in a single subject during and following the 2-hr intravenous infusion of ethanol. Key: $\boldsymbol{\Delta}, 720 \mathrm{ml}$ of $4 \% \mathrm{~V} / \mathrm{V} ; \bullet, 720 \mathrm{ml}$ of $8 \% \mathrm{~V} / \mathrm{V}$ ethanol in physiological saline. Dotted lines through points are drawn by sight. Solid lines were obtained by least-squares linear regression and have the slopes indicated on the figure.

that at lower concentrations the terminal blood alcohol time course becomes nonlinear ${ }^{21,} \mathbf{2 6}$, 27, 29; and (2) the entire concentration-time courses both during and after constant-rate intravenous infusion of ethanol have not been reported in similar detail; consequently, an appropriate pharmacokinetic model could not be elaborated. To correct these shortcomings, we undertook to provide data that would define the total time courses of blood ethanol concentrations, both during the 2-hr constant-rate intravenous infusion of ethanol and subsequent to the end of the infusion.

\section{Methods}

Protocol. Seven normal adult male volunteers between the ages of 21 and 54 and weighing between 70 and $86 \mathrm{~kg}$, with normal vital signs and laboratory testing values, were selected. Two separate studies were performed. In the first, a single subject $(70 \mathrm{~kg})$ received $720 \mathrm{ml}$ of an $8 \% \mathrm{~V} / \mathrm{V}$ ethanol solution in normal saline and $720 \mathrm{ml}$ of a $4 \% \mathrm{~V} / \mathrm{V}$ ethanol solution in normal saline, both as 2-hr, constant-rate intravenous infusions, at 1-wk intervals. In the second study, $720 \mathrm{ml}$ of an $8 \%$ $\mathrm{V} / \mathrm{V}$ ethanol solution in normal saline was infused in each of 6 subjects at a constant rate of $6 \mathrm{ml} / \mathrm{min}$ by a Harvard Peristaltic intravenous pump (Model 2671) over $2 \mathrm{hr}$. All subjects fasted from $10 \mathrm{hr}$ prior to the start of the infusion until $1 \mathrm{hr}$ postinfusion. No alcoholic beverages were consumed from 3 days preceding the infusions until the completion of the study. The total amount of ethanol infused in the first study was $57.6 \mathrm{ml}$ and $28.8 \mathrm{ml}$, equivalent to 44.3 and $23.5 \mathrm{gm}$ of absolute alcohol, for the $8 \%$ and $4 \%$ infusions, respec- 
Table III. Estimated parameters and measures of fit for the simultaneous nonlinear least-squares fitting * of observed concentrations to the 1-compartment open model with zero order input and Michaelis-Menten elimination kinetics

\begin{tabular}{|c|c|c|c|c|c|c|c|c|}
\hline \multirow[b]{2}{*}{ Subject } & \multirow[b]{2}{*}{$V_{m}[m g /(m l \times h r)]$} & \multirow[b]{2}{*}{$K_{m}(m g / m l)$} & \multicolumn{2}{|c|}{$\begin{array}{c}\text { Area } \\
{[(m g / m l) \times h r]}\end{array}$} & \multicolumn{2}{|c|}{$V$} & \multicolumn{2}{|c|}{$\begin{array}{l}\text { Measures of } \\
\quad \text { fit } \$\end{array}$} \\
\hline & & & Obs. $\dagger$ & Calc'd. $\ddagger$ & $L$ & \% body wt & $r^{2}$ & Corr. \\
\hline 1 & $0.253(0.009) \|$ & $0.108 \quad(0.005)$ & 1.986 & 1.938 & $42.9(1.4)$ & 53.9 & 0.987 & 0.987 \\
\hline 2 & $0.260(0.010)$ & $0.103 \quad(0.006)$ & 1.738 & 1.690 & $46.1(1.3)$ & 52.0 & 0.992 & 0.992 \\
\hline 3 & $0.238(0.006)$ & $0.0762(0.0049)$ & 2.586 & 2.527 & $39.7(1.0)$ & 49.9 & 0.993 & 0.992 \\
\hline 4 & $0.210(0.009)$ & $0.0983(0.0064)$ & 3.025 & 2.938 & $39.2(1.4)$ & 52.3 & 0.983 & 0.983 \\
\hline 5 & $0.192(0.006)$ & $0.0302(0.0019)$ & 1.941 & 1.888 & $47.2(1.0)$ & 63.1 & 0.995 & 0.993 \\
\hline 6 & $0.241(0.006)$ & $0.0767(0.0044)$ & 2.392 & 2.351 & $41.2(0.8)$ & 49.8 & 0.996 & 0.993 \\
\hline Mean & 0.232 & 0.0821 & & & 42.7 & 53.5 & & \\
\hline SD & 0.026 & 0.0287 & & & 3.3 & 5.0 & & \\
\hline
\end{tabular}

*Time intervals used to make initial estimates of $V_{m}$ and $K_{m}$ for the fittings were 3-7, 3-6.5, 4.5-7.25, 6-8.5, 5-6.25, and 3.5-7 hr for Subjects 1 through 6 , respectively.

t Area under the observed concentration-time curve estimated by trapezoidal rule.

Model-predicted area under the concentration-time curve.

$\S \mathrm{r}^{2}=\left[\Sigma \mathrm{C}^{2}-\Sigma(\hat{\mathrm{C}}-\mathrm{C})^{2}\right] / \Sigma \mathrm{C}^{2}$; Corr. = correlation coefficient for linear regression of $\hat{\mathrm{C}}$ on $\mathrm{C}$.

$\|$ Bracketed numbers are standard deviations of the estimated parameters.

tively. The doses $(\mathrm{gm} / \mathrm{kg})$ for the 6 subjects in the second study are listed in Table I.

Eight to 10 capillary blood samples were collected just prior to and during the 2-hr infusion period with the last sample being taken at the exact time the infusion pump was turned off. Ten to 21 capillary blood samples were collected after the infusion pump was shut off, at strategic sampling times, to adequately define the total time course of blood ethanol concentrations. After lancing a fingertip, each sample was collected in a disposable calibrated capillary tube. The blood samples were mixed with equal volumes of internal standard solution in 0.4-ml polypropylene test tubes. The samples from the first study were stored in the polypropylene test tubes in a refrigerator $\left(4^{\circ} \mathrm{C}\right)$ until assayed. The samples from the second study were transferred to 6-ml amber glass serum vials after mixing with the internal standard solution, and immediately refrigerated until assayed.

Analytical methods. Capillary blood samples $(20 \mu \mathrm{l})$ from the first study were analyzed for ethyl alcohol by a modification ${ }^{22}$ of the direct injection technique reported by Wagner and Patel. ${ }^{26}$ Capillary blood samples of 50 $\mu \mathrm{L}$ from the second study were assayed for ethanol according to the head-space gas chro- matographic method of Wilkinson, Wagner, and Sedman..$^{30}$ The analyses were performed on a Varian 2100 gas chromatograph equipped with flame ionization detectors. All samples were assayed on the same day that they were collected.

Analysis of experimental data. The area under the concentration-time curves from the first (single subject) study were calculated for both the $4 \%$ and $8 \%$ ethanol infusions. The blood alcohol concentration-time course from the $8 \%$ infusion in this study was used to determine appropriate sampling times for the second (6 subjects) study and to obtain information on the area-dose relationship in man following a constant-rate intravenous infusion.

Individual blood ethanol concentrations for the 6 subjects in the second study were fitted to the one-compartment open model with zero order input and Michaelis-Menten elimination kinetics shown in Schema I. With this model, the blood ethanol concentration, $\mathrm{C}$, at any time during the infusion is described by Equation 1, and by Equation 2 after the infusion ceases.

$$
\begin{gathered}
\frac{d C}{d t}=\frac{k_{o}}{V}-\frac{V_{m} C}{K_{m}+C} \\
\frac{d C}{d t}=-\frac{V_{m} C}{K_{m}+C}
\end{gathered}
$$




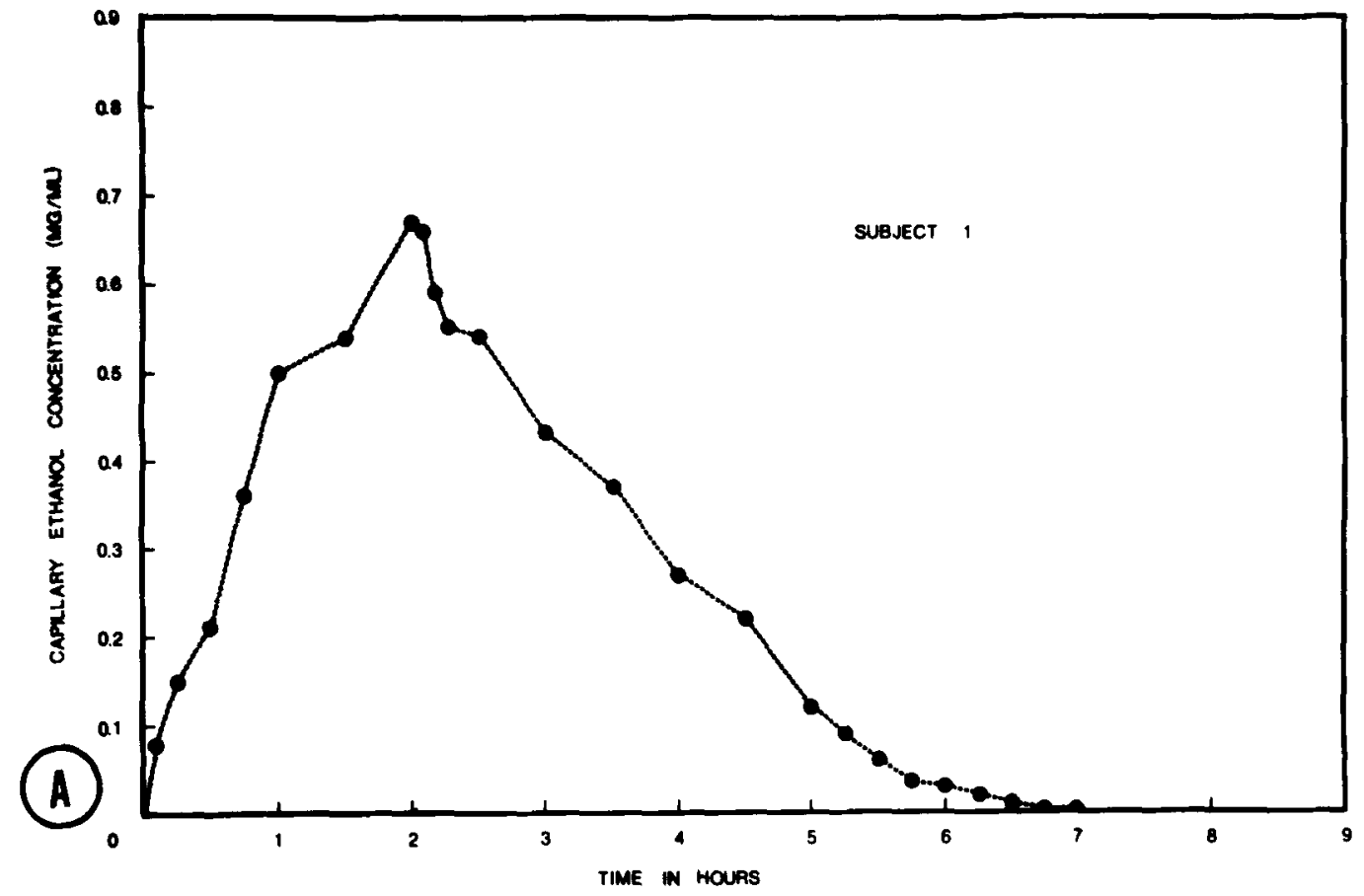

Fig. 2. A-C, Capillary blood ethanol concentrations measured in Subjects 1, 2, and 3 during and following the $2-\mathrm{hr}$ intravenous infusion of $720 \mathrm{ml}$ of $8 \% \mathrm{~V} / \mathrm{V}$ ethanol in physiological saline. Points are just joined by linear segments.

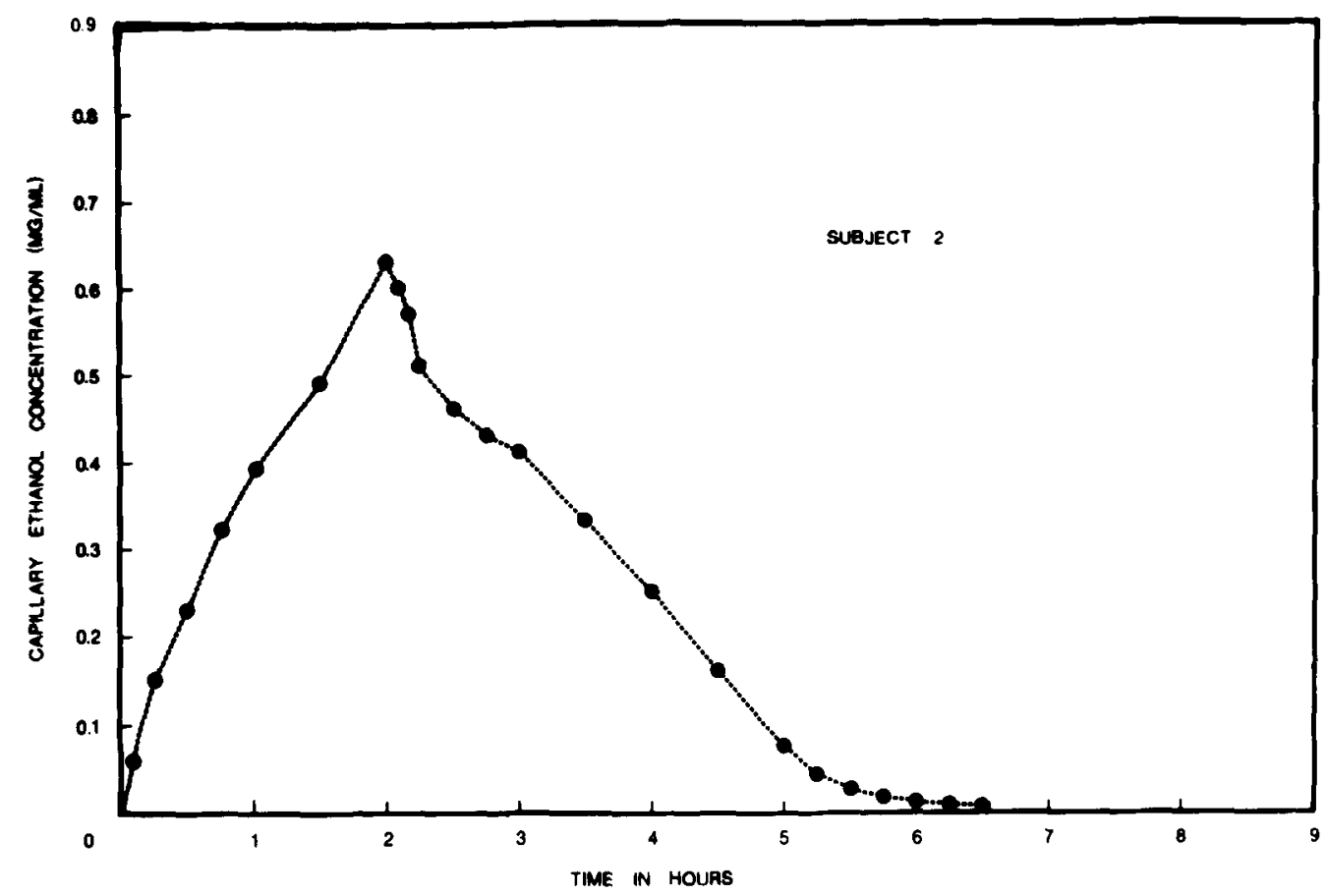

Fig. 2, B. For legend see above. 


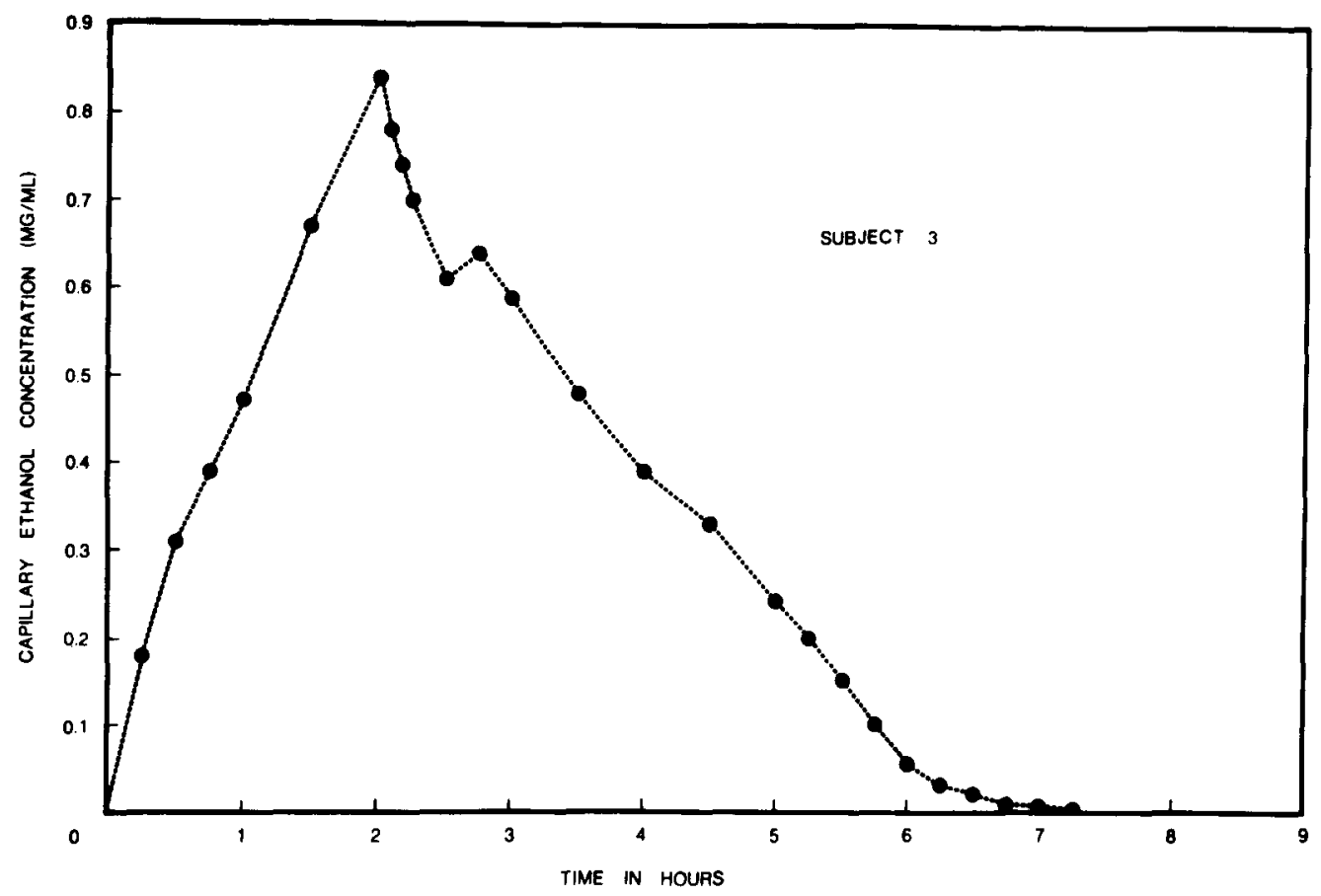

Fig. 2, C. For legend see preceding page.

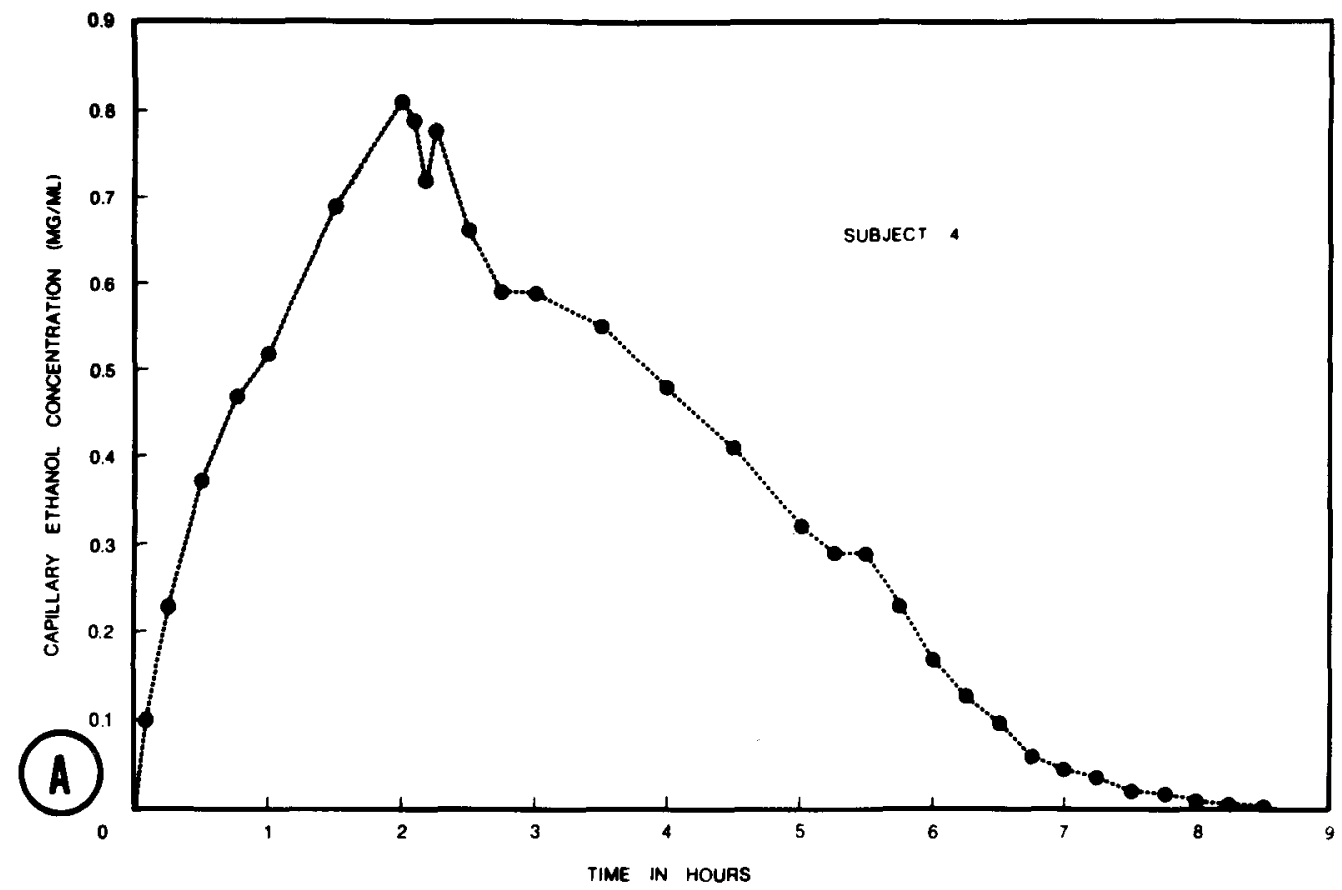

Fig. 3. A-C, Capillary blood ethanol concentrations measured in Subjects 4,5 , and 6 during and following the 2-hr intravenous infusion of $720 \mathrm{ml}$ of $8 \% \mathrm{~V} / \mathrm{V}$ ethanol in physiological saline. Points are just joined by linear segments. 


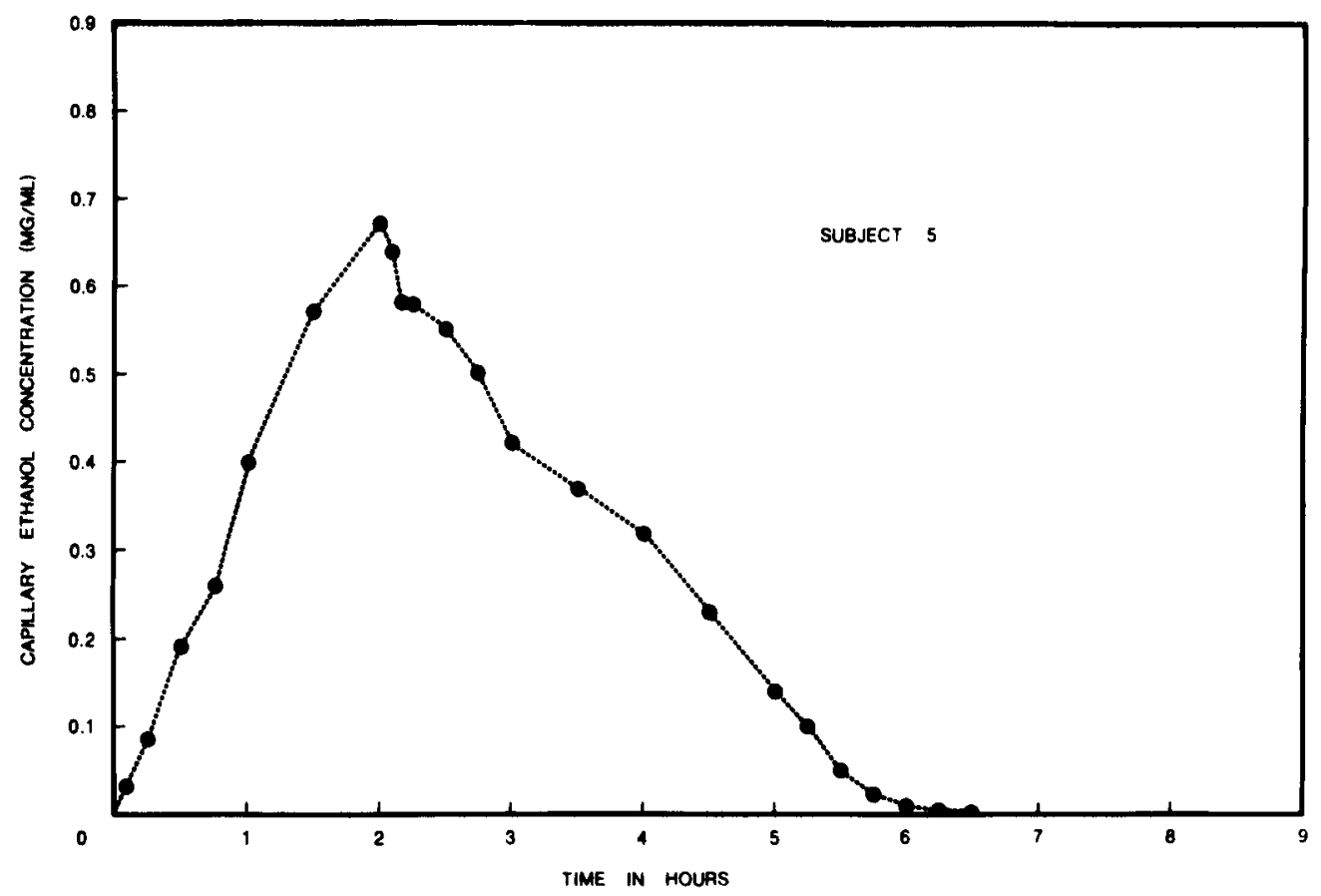

Fig. 3, B. For legend see opposite page.

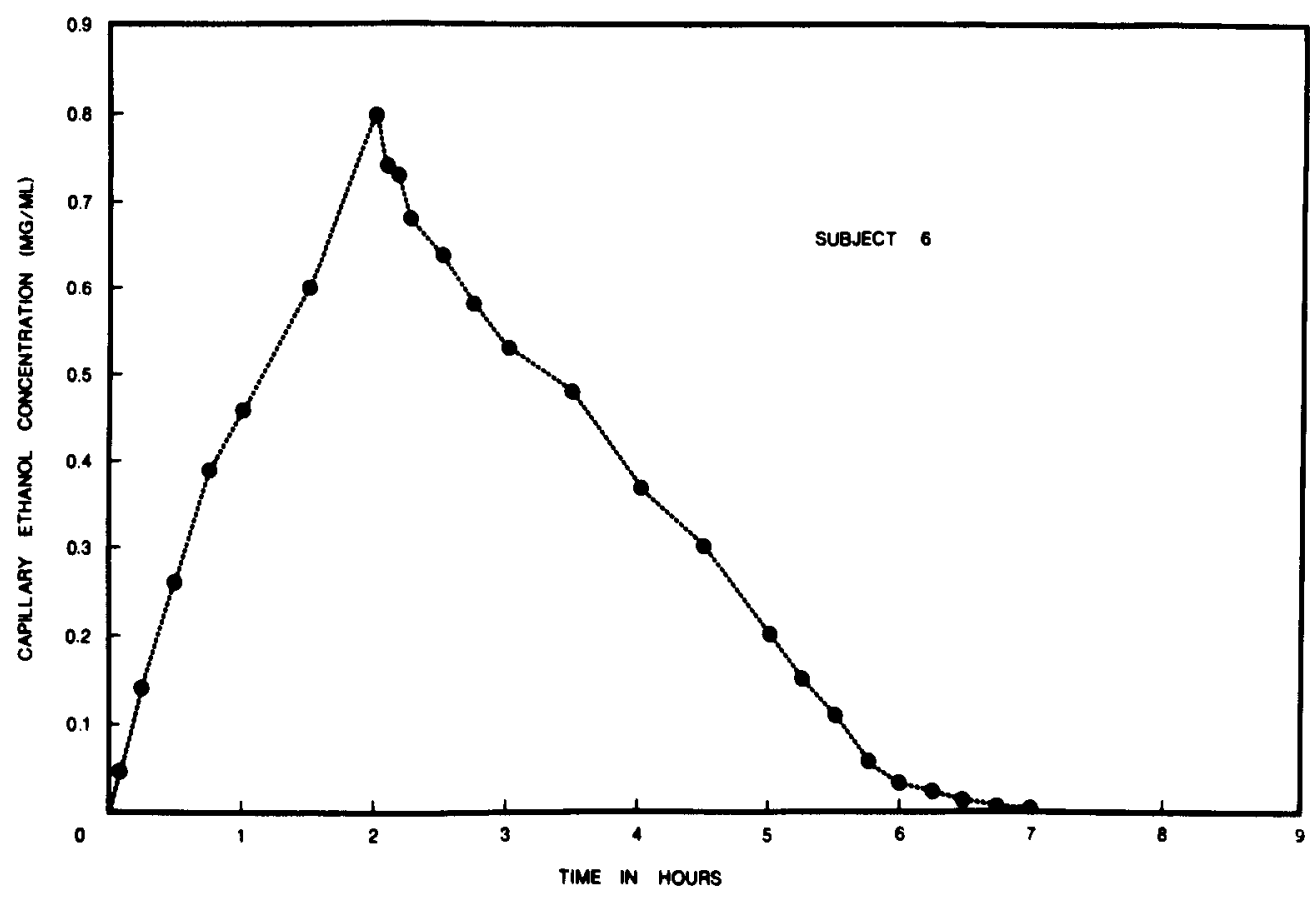

Fig. 3, C. For legend see opposite page. 
Table IV. Comparison of observed and model-predicted capillary blood ethanol concentrations

\begin{tabular}{|c|c|c|c|c|c|c|c|c|}
\hline \multicolumn{9}{|c|}{ Capillary blood ethanol concentrations $(\mathrm{mg} / \mathrm{ml})$} \\
\hline \multirow{2}{*}{$\begin{array}{l}\text { Time } \\
(h r)\end{array}$} & \multicolumn{2}{|c|}{ Subject 1} & \multicolumn{2}{|c|}{ Subject 2} & \multicolumn{2}{|c|}{ Subject 3} & \multicolumn{2}{|c|}{ Subject 4} \\
\hline & Obs. & Pred. & Obs. & Pred. & Obs. & Pred. & Obs. & Pred. \\
\hline 0.0 & 0.0 & 0.0 & 0.0 & 0.0 & 0.0 & 0.0 & 0.0 & 0.0 \\
\hline 0.083 & 0.077 & 0.040 & 0.062 & 0.038 & - & - & 0.10 & 0.045 \\
\hline 0.25 & 0.15 & 0.11 & 0.15 & 0.10 & 0.18 & 0.12 & 0.23 & 0.13 \\
\hline 0.5 & 0.21 & 0.20 & 0.23 & 0.19 & 0.31 & 0.23 & 0.37 & 0.24 \\
\hline 0.75 & 0.36 & 0.29 & 0.32 & 0.27 & 0.39 & 0.33 & 0.47 & 0.34 \\
\hline 1.0 & 0.50 & 0.37 & 0.39 & 0.35 & 0.47 & 0.43 & 0.52 & 0.44 \\
\hline 1.5 & 0.54 & 0.53 & 0.49 & 0.49 & 0.67 & 0.63 & 0.69 & 0.64 \\
\hline 2.0 & 0.67 & 0.68 & 0.63 & 0.63 & 0.84 & 0.82 & 0.81 & 0.84 \\
\hline 2.083 & 0.66 & 0.66 & 0.60 & 0.61 & 0.78 & 0.80 & 0.79 & 0.82 \\
\hline 2.167 & 0.59 & 0.65 & 0.57 & 0.59 & 0.74 & 0.78 & 0.72 & 0.81 \\
\hline 2.25 & 0.55 & 0.63 & 0.51 & 0.57 & 0.70 & 0.77 & 0.78 & 0.79 \\
\hline 2.5 & 0.54 & 0.57 & 0.46 & 0.52 & 0.61 & 0.71 & 0.66 & 0.75 \\
\hline 2.75 & - & - & 0.43 & 0.47 & 0.64 & 0.66 & 0.59 & 0.70 \\
\hline 3.0 & 0.43 & 0.47 & 0.42 & 0.41 & 0.59 & 0.60 & 0.59 & 0.65 \\
\hline 3.5 & 0.37 & 0.37 & 0.33 & 0.31 & 0.48 & 0.50 & 0.55 & 0.56 \\
\hline 4.0 & 0.27 & 0.28 & 0.25 & 0.22 & 0.39 & 0.40 & 0.48 & 0.47 \\
\hline 4.5 & 0.22 & 0.19 & 0.16 & 0.14 & 0.33 & 0.30 & 0.41 & 0.39 \\
\hline 5.0 & 0.12 & 0.12 & 0.074 & 0.073 & 0.24 & 0.21 & 0.32 & 0.31 \\
\hline 5.25 & 0.089 & 0.086 & 0.043 & 0.049 & 0.20 & 0.17 & 0.29 & 0.27 \\
\hline 5.5 & 0.057 & 0.060 & 0.027 & 0.031 & 0.15 & 0.13 & 0.29 & 0.23 \\
\hline 5.75 & 0.034 & 0.040 & 0.016 & 0.019 & 0.10 & 0.093 & 0.23 & 0.19 \\
\hline 6.0 & 0.029 & 0.026 & 0.012 & 0.011 & 0.054 & 0.063 & 0.17 & 0.16 \\
\hline 6.25 & 0.020 & 0.016 & 0.0066 & 0.0061 & 0.030 & 0.039 & 0.13 & 0.13 \\
\hline 6.5 & 0.010 & 0.0093 & 0.0031 & 0.0033 & 0.020 & 0.022 & 0.10 & 0.10 \\
\hline 6.75 & 0.0036 & 0.0053 & - & - & 0.0086 & 0.012 & 0.060 & 0.076 \\
\hline 7.0 & 0.0029 & 0.0030 & - & - & 0.0057 & 0.0058 & 0.049 & 0.055 \\
\hline 7.25 & - & - & - & - & 0.0028 & 0.0028 & 0.037 & 0.038 \\
\hline 7.5 & - & - & - & - & - & - & 0.024 & 0.026 \\
\hline 7.75 & - & - & - & - & - & - & 0.017 & 0.016 \\
\hline 8.0 & - & - & - & - & - & - & 0.011 & 0.010 \\
\hline 8.25 & - & - & - & - & - & - & 0.0053 & 0.0062 \\
\hline 8.5 & - & - & - & - & - & - & 0.0023 & 0.0037 \\
\hline
\end{tabular}

Obs.: observed.

Pred.: predicted.

In Schema 1 and Equations 1 and $2, \mathrm{k}_{0}$ is the infusion rate $(\mathrm{mg} / \mathrm{hr}), \mathrm{V}$ is the volume of distribution of ethanol in the body $(\mathrm{ml}), \mathrm{V}_{\mathrm{m}}$ is the maximal velocity $[\mathrm{mg} /(\mathrm{ml} \times \mathrm{hr})]$, and $\mathrm{K}_{\mathrm{m}}$ is the Michaelis constant $[\mathrm{mg} / \mathrm{ml}]$ for the elimination of ethanol from the body. All the $\mathrm{C}, \mathrm{t}$ data for each subject were fitted simultaneously by a numerical integration method, utilizing Equation 1 for "during the infusion", data and Equation 2 for "postinfusion" data. The nonlinear least-squares regression program, NONLIN, ${ }^{15}$ and an IBM 360/67 digital computer were employed. Parameter estimates of $\mathrm{V}, \mathrm{V}_{\mathrm{m}}$, and $\mathrm{K}_{\mathrm{m}}$ were obtained and the area under the concentration-time curves from zero to $T$ (the last sampling time) as estimated by trapezoidal rule was determined. This area is within about $1 \%$ of the total area since concentrations were followed down to near endogenous levels.

The Wagner-Nelson method ${ }^{25}$ modified for Michaelis-Menten elimination kinetics ${ }^{26}$ (Equation 3) was applied to the concentration-time data for the 6 subjects to obtain independent estimates of the infusion rates. If the one-compartment open model with zero order input 


\begin{tabular}{|c|c|c|c|}
\hline \multicolumn{2}{|c|}{ Subject 5} & \multicolumn{2}{|c|}{ Subject 6} \\
\hline Obs. & Pred. & Obs. & Pred. \\
\hline 0.0 & 0.0 & 0.0 & 0.0 \\
\hline 0.031 & 0.035 & 0.046 & 0.044 \\
\hline 0.085 & 0.096 & 0.14 & 0.12 \\
\hline 0.19 & 0.18 & 0.26 & 0.22 \\
\hline 0.26 & 0.26 & 0.39 & 0.32 \\
\hline 0.40 & 0.34 & 0.46 & 0.42 \\
\hline 0.57 & 0.50 & 0.60 & 0.60 \\
\hline 0.67 & 0.65 & 0.80 & 0.78 \\
\hline 0.64 & 0.64 & 0.74 & 0.77 \\
\hline 0.58 & 0.62 & 0.73 & 0.75 \\
\hline 0.58 & $0.6 \mathrm{l}$ & 0.68 & 0.73 \\
\hline 0.55 & 0.56 & 0.64 & 0.68 \\
\hline 0.50 & 0.52 & 0.58 & 0.62 \\
\hline 0.42 & 0.47 & 0.53 & 0.57 \\
\hline 0.37 & 0.38 & 0.48 & 0.46 \\
\hline 0.32 & 0.29 & 0.37 & 0.36 \\
\hline c. 23 & 0.21 & 0.30 & 0.27 \\
\hline 0.14 & 0.13 & 0.20 & 0.18 \\
\hline 0.10 & 0.089 & 0.15 & 0.14 \\
\hline 0.050 & 0.055 & 0.11 & 0.10 \\
\hline 0.021 & 0.028 & 0.057 & 0.068 \\
\hline 0.010 & 0.010 & 0.034 & 0.043 \\
\hline 0.0042 & 0.0026 & 0.024 & 0.025 \\
\hline- & - & 0.014 & 0.013 \\
\hline- & - & 0.0065 & 0.0065 \\
\hline- & - & 0.0034 & 0.0031 \\
\hline - & - & - & - \\
\hline- & - & - & - \\
\hline - & - & - & - \\
\hline- & - & - & - \\
\hline - & - & - & - \\
\hline- & - & - & - \\
\hline
\end{tabular}

and Michaelis-Menten elimination kinetics is obeyed, then:

$$
\frac{A_{T}}{V}=\frac{k_{0}}{V} \cdot T=C_{T}+\int_{0}^{T}\left\{\frac{V_{m} C}{K_{m}+C}\right\} d t .
$$

In Equation 3, $\mathrm{A}_{\mathrm{T}}$ is the cumulative amount infused to some time $\mathrm{T}, \mathrm{V}$ is the volume of distribution, $k_{0}$ is the infusion rate (mass/time), $\mathrm{C}_{\mathrm{T}}$ is the blood ethanol concentration at time $T$, and $V_{m}$ and $K_{m}$ are the Michaelis-Menten parameters described above. A plot of $A_{T} / V$ vs $\mathrm{T}$ (while the infusion pump is on) gave a straight line for each subject with the slope equal to $\mathrm{k}_{\mathrm{o}} / \mathrm{V}$, the infusion rate divided by the volume of distribution of ethanol.

\section{Results}

Fig. 1 depicts observed capillary blood ethanol concentration-time data in the single subject during and following the constant-rate intravenous infusion of 2 different doses of ethanol. Figs. 2 and 3 show the observed concentration, time $(\mathrm{C}, \mathrm{t})$ data in the 6 subjects during and postinfusion of $720 \mathrm{ml}$ of an $8 \%$ $\mathrm{V} / \mathrm{V}$ solution of ethanol in physiological saline. Table I gives a summary of the body weights, $\mathrm{gm} / \mathrm{kg}$ doses, areas under the $\mathrm{C}, \mathrm{t}$ curves, and peak concentrations for the 6 subjects. Table II summarizes the means, standard deviations, and coefficients of variation for the 6 subjects at each sampling time during and subsequent to the infusion of ethanol.

The results of the pharmacokinetic analysis are given in Tables III through V. Table III lists the estimated parameters $\mathrm{V}_{\mathrm{m}}, \mathrm{K}_{\mathrm{m}}$, and $\mathrm{V}$, along with measures of fit, and compares observed and model-predicted areas under the concentration-time curves. Table IV compares observed and model-predicted capillary blood ethanol concentrations in the 6 subjects.

Table $\mathrm{V}$ provides a comparison of the $\mathrm{k}_{0} / \mathrm{V}$ values obtained from results of application of the modified Wagner-Nelson method and from the known infusion rate divided by the volume of distribution of each subject estimated in the simultaneous fittings.

\section{Discussion}

The concentration-time data in Figs 1 to 3 were characterized by the following trends: (1) an abrupt decline in the one subject (Fig. 1) and less abrupt declines in the other 6 subjects (Figs. 2 and 3)(apparently caused by distribution effects) in ethanol concentrations occurred immediately after the infusion ceased; (2) a pseudolinear phase starting shortly after the infusion pump was turned off, which persisted until ethanol concentrations decreased to about $0.20 \mathrm{mg} / \mathrm{ml}$; (3) a curvilinear phase was present below ethanol concentrations of about $0.20 \mathrm{mg} / \mathrm{ml}$; (4) the area under the ethanol concentration-time curve increased disproportionately with an increase in dose in the subject 
Table V. Comparison of $k_{o} / V$ values obtained from estimation by modified Wagner-Nelson method and from known infusion rate

\begin{tabular}{c|c|c|c}
\hline & \multicolumn{2}{|c|}{$k_{0} / V$} & \\
\cline { 2 - 3 } & $\begin{array}{c}\text { Estimated by } \\
\text { modified } \\
\text { Wagner-Nelson } \\
(W-N) \\
\text { Subject }\end{array}$ & {$\left[\begin{array}{c}\text { Infusion } \\
\text { rate } \\
V^{*}\end{array}\right]$} & $\begin{array}{c} \\
\text { \%ethod error } \\
\text { with } \\
W-N \text { method }\end{array}$ \\
\hline 1 & 0.553 & 0.519 & +6.6 \\
2 & 0.521 & 0.497 & +4.8 \\
3 & 0.629 & 0.597 & +5.5 \\
4 & 0.624 & 0.577 & +8.1 \\
5 & 0.516 & 0.493 & +4.7 \\
6 & 0.601 & 0.580 & +3.6
\end{tabular}

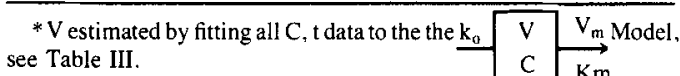

given the two doses. A 1.9-fold increase in dose $(\mathrm{gm} / \mathrm{kg})$ resulted in a 3.5 -fold increase in area under the $\mathrm{C}, \mathrm{t}$ curve when the 2 different doses of ethanol were administered to this single subject by constant-rate intravenous infusion.

These findings suggest that the pharmacokinetics of ethanol in certain subjects (exemplified by the data in Fig. 1) would best be described by a multicompartmental model with Michaelis-Menten elimination kinetics. Sedman $^{20}$ attempted to analyze the data obtained following the two infusions (Fig. 1) to several multicompartmental models with limited success. Based on the fittings of the data from the 6 subjects in the second study (see Tables III and IV), the one-compartment open model with zero input and Michaelis-Menten elimination is an operationally useful model to describe the pharmacokinetics of ethanol (during and postinfusion) in man. However, it should be noted (Table IV) that the modelpredicted concentrations are higher than the observed concentrations just after cessation of the infusion, suggesting multicompartmental disposition kinetics less pronounced in these 6 subjects than in the single subject (Fig. 1).

The slope of the pseudolinear decline of the blood alcohol concentrations has been shown to be dose-dependent, such that the slope in- creases with an increase in dose. ${ }^{27,}{ }^{29}$ The slope of the pseudolinear phase following the intravenous infusion of the $8 \%$ ethanol solution in the single subject was higher $(p<0.001)$ than the slope subsequent to the infusion of the $4 \%$ ethanol solution (see Fig. 1).

It has been assumed ${ }^{9,} 18,26$ that alcohol distributes into total body water, which in the average man represents about two thirds of body weight. The estimates of $\mathrm{V}$ (in Table III) obtained in the computer fitting of these data averaged $42.7 \mathrm{~L}$ or $53.5 \%$ (range: 49.9 to $63.1 \%$ ) of body weight. This panel of 8 subjects had an average body weight of 80.1 $\mathrm{kg}$. In another study, ${ }^{29}$ the estimated $\mathrm{V}$ was $44.1 \mathrm{~L}$ or $59.1 \%$ of the average body weight of a panel of 8 subjects $(74.6 \mathrm{~kg})$. Both of these estimates agree with values given for total body water, the estimates of which vary, depending on both age and body weight. ${ }^{1}$ The infusion rate divided by the volume of distribution estimated via the modified WagnerNelson method, Table $\mathrm{V}$ ) provided slightly higher estimates of $\mathrm{k}_{0} / \mathrm{V}$ (average: $5.5 \%$ error) compared with the known infusion rate divided by the volume of distribution estimated in the simultaneous computer fittings.

The average value of $V_{m}, 0.232 \mathrm{mg} /(\mathrm{mg}$ $\times \mathrm{hr}$ ), in Table III, is very close to the estimated value of 0.202 obtained by the fitting of all of the mean blood alcohol concentration data following the oral administration of 4 different doses of ethanol to 8 other fasting subjects in another study. These latter data were fitted to the one-compartment open model with Michaelis-Menten elimination kinetics and input into blood subject to feedback regulation of gastric emptying rate. The average value of $\mathrm{K}_{\mathrm{m}}, 0.0821 \mathrm{mg} / \mathrm{ml}$, is almost identical to the estimated value of 0.0818 obtained in the same study. ${ }^{29}$

\section{References}

1. Altmen, P. L., and Dittmer, D. S., editors: Blood and other body fluids, Bethesda, Md., 1971, Federation of American Societies of Experimental Biology, pp. 496-497.

2. Dundee, J. W.: Intravenous ethanol anesthesia: A study of dosage and blood levels, Anesth. Analg. (Cleve.) 49:467-475, 1970.

3. Dundee, J. W., and Isaac, M.: Clinical studies 
of induction agents. XXIX. Ethanol, Br. J. Anaesth. 41:1063-1069, 1969.

4. Dundee, J. W., Isaac, M., and Clark, R. S. J.: Use of alcohol in anesthesia, Anesth. Analg. Curr. Res. 48:665-669, 1969.

5. Dundee, J. W., Isaac, M., Pandit, S. K., and McDowell, S. A.: Clinical studies of induction agests. XXXIV. Further investigations with ethanol, Br. J. Anaesth. 42:300-310, 1970.

6. Dundee, J. W., Isaac, M., and Taggert, J.: Blood ethanol levels following rapid intravenous infusion, Q. J. Stud. Alcohol 32:741-747, 1971.

7. Dundee, J. W., Knox, J. W. D., and Isaac, M.: Blood, urine, and breath levels after rapid intravenous infusion of ethanol, Br. Med. J. 3: 552-554, 1970.

8. Eggleton, M. G.: Some factors affecting the metabolic rate of alcohol, J. Physiol. 98:239$254,1940$.

9. Forney, R. B.: General pharmacology of alcohol, Abstracts of symposia and contributed papers presented to the APhA Academy of Pharmaceutical Sciences at the 118th Annual Meeting of the American Pharmaceutical Association, San Francisco, Calif., March 27. April 2, vol. 1, no. 1, 1971, p. 28.

10. Hawkins, R. D., and Kalant, H.: The metabolism of ethanol and its metabolic effects, Pharmacol. Rev. 24:67-157, 1972.

11. Idanpään-Heikkila, J., Jouppila, P., Åkerblom, H. K., Isoaho, R., Kauppila, E., and Koivisto, M.: Elimination and metabolic effects of ethanol in mother, fetus and newborn infant, Am. J. Obstet. Gynecol. 112:387-393, 1972.

12. Korsten, M. A., Matsuzaki, S., Feinman, L., and Lieber, C. S.: High blood acetaldehyde levels after ethanol administration. Differences between alcoholic and nonalcoholic subjects, N. Engl. J. Med. 292:386-389, 1975.

13. Kostelnik, M. E., and Iber, F. L.: Correlation of alcohol and tolbutamide blood clearance rates with microsomal alcohol-metabolizing enzyme activity, Am. J. Clin. Nutr. 26:161-164, 1973.

14. Lundquist, F., and Wolthers, H.: The kinetics of alcohol elimination in man, Acta Pharmacol. Toxicol. 14:265-289, 1958.

15. Metzler, C. M.: Biostatistical Technical Report 7292/69/7292/005, Kalamazoo, Mich., Nov. 25, 1969, The Upjohn Company.

16. Michaelis, L., and Menten, M. L.: Die kinetik der invertinwirkung, Biochem. Z. 49:333-369, 1913.

17. Newman, H. W., Lehman, A. J., and Cutting, W. C.: Effect of dosage on rate of disappearance of alcohol from the blood stream, J. Pharmacol. Exp. Ther. 61:58-61, 1937.

18. Pawon, G. S. L., and Hoult, W. H.: The determination of total body water in man by ethanol dilution, Biochem. J. 87:6P-7P, 1963.

19. Raskin, N. H.: Alcoholism or acetaldehydism, N. Engl. J. Med. 292:422-423, 1975.

20. Sedman, A. J.: Blood levels of ethanol and a decision-making pharmacokinetic digital computer program, Ph.D. thesis, Ann Arbor, Mich., 1974, The University of Michigan.

21. Sedman, A. J., Wilkinson, P. K., Sakmar, E., Weidler, D. J., and Wagner, J. G.: Effects of food on the absorption and metabolism of ethyl alcohol. Submitted for publication in J. Stud. Alcohol.

22. Sedman, A. J., Wilkinson, P. K., and Wagner, J. G.: Concentrations of ethanol in two segments of the vascular system. Tentitively accepted, Aug. 4, 1975, for publication in J. Forensic Sci.

23. Shah, M. W., Clancy, B. A. and Iber, F. L.: Comparison of blood clearance of ethanol and tolbutamide and the activity of hepatic ethanoloxidizing and drug-metabolizing enzymes in chronic alcoholic subjects, Am. J. Clin. Nutr. 25:135-139, 1972.

24. Wagner, J. G.: Fundamentals of clinical pharmacokinetics, Hamilton, Ill., 1975, Drug Intelligence Publications, p. 200.

25. Wagner, J. G., and Nelson, E.: Percent absorbed plots derived from blood level and/or urinary excretion data, J. Pharm. Sci. 52:610$611,1963$.

26. Wagner, J. G., and Patel, J. A.: Variations in absorption and elimination rates of ethyl alcohol in a single subject, Res. Commun. Chem. Pathol. Pharmacol. 4:61-76, 1972.

27. Wagner, J. G., Wilkinson, P. K., Sedman, A. J., Kay, D. R., and Weidler, D. J.: Elimination of alcohol from the blood of man. Submitted for publication in J. Pharm. Sci., July, 1975.

28. Widmark, E. M. P.: Verteilung und umwandlung des äthylalkohols im organismus des hundes, Biochem. Z. 267:128-134, 1933.

29. Wilkinson, P. K., Sedman, A. J., Sakmar, E., Kay, D. R., and Wagner, J. G.: Fasting blood ethanol concentrations following the oral administration of four different doses of ethanol, Submitted for publication in J. Stud. Alcohol.

30. Wilkinson, P. K., Wagner, J. G., and Sedman, A. J.: A sensitive head-space gas chromatographic method for the determination of ethanol utilizing capillary blood samples, Anal. Chem. 47:1506-1510, 1975. 